\title{
Longwall Retreat and Creep Measurement Based on UWB Radar Imaging Method
}

\author{
Shijia Wang $\mathbb{D}^{1,2}$ Shibo Wang $\mathbb{D}^{1,2}$ and Wanli Liu $\mathbb{D}^{1,2}$ \\ ${ }^{1}$ School of Mechanical and Electronic Engineering, China University of Mining and Technology, Xuzhou, China \\ ${ }^{2}$ Intelligent Mining Equipment Collaborative Innovation Center, China University of Mining and Technology, Xuzhou, China
}

Correspondence should be addressed to Shibo Wang; wangshb@cumt.edu.cn and Wanli Liu; 4830@cumt.edu.cn

Received 4 November 2019; Revised 6 January 2020; Accepted 30 March 2020; Published 11 May 2020

Academic Editor: Giacomo Falcucci

Copyright (C) 2020 Shijia Wang et al. This is an open access article distributed under the Creative Commons Attribution License, which permits unrestricted use, distribution, and reproduction in any medium, provided the original work is properly cited.

\begin{abstract}
The measurement of longwall retreat and creep displacements is of great significance for the safety production of a coal mine. In order to reliably and accurately obtain the longwall retreat and creep displacements, this paper proposes an ultrawideband (UWB) radar imaging method. The bolt plates fixed in the roadway coal wall are imaged as the target points. First, a signal model is built, and a modified nonlinear chirp scaling (NLCS) imaging algorithm is designed to obtain the high-resolution image. Then, the retreat and creep displacements are estimated based on the imaging results. Finally, simulation and experiment are performed. The simulation results show that the radar imaging method is theoretically feasible to measure the retreat and creep displacements. The measurement errors in the experiment are $0.058 \mathrm{~m}$ and $0.040 \mathrm{~m}$, respectively. In the experiment, the radar velocity fluctuation and signal attenuation cause the target azimuth and range errors in the imaging results, which makes the measurement errors in the experiment larger than that in the simulation. This method requires no additional roadway information except for the bolt plates fixed in the coal wall. In addition, the signal propagation of UWB radar is rarely affected by the dust and moisture in the harsh environment.
\end{abstract}

\section{Introduction}

Longwall mining is a primary method for extracting coal from underground mine, as it can protect worker safety and improve mining productivity. The typical plane view of a longwall mining panel is shown in Figure 1(a). Two long roadways are excavated to form the boundaries of the longwall panel $[1,2]$. At the end of the roadway, a shearer, an armored face conveyor (AFC), and a roof support system are installed across the back of the panel, creating the longwall face. The shearer moves back and forth along a rail associated with the AFC to cut the coal seam, while the roof support system supports the coal seam roof. As the shearer travels, the AFC is pushed along the retreat direction by the larger hydraulic push arms attached to the roof support system for the next cutting cycle $[3,4]$. A cutting cycle refers to the process in which the shearer moves the whole length of the longwall face. The longwall retreat displacement is the difference of AFC position along the retreat direction between the adjacent cutting cycles shown in Figure 2. Due to the interaction between the coal seam and equipment during the mining progress, different sections of the longwall face may have different retreat distances, causing deviations in the longwall face profile. Gradually, one part of the longwall face will lag behind the whole advancing progress, potentially causing the roof to fail. In addition, the interaction between the coal seam and equipment in variation pressures also leads to the sideway slippage of equipment across the longwall face, called the longwall creep. This prevents the retreat of longwall face. The longwall creep displacement refers to the difference of AFC position along the moving direction between the adjacent cutting cycles shown in Figure 2. Therefore, it is necessary to monitor the longwall retreat and creep displacements. Recently, researchers have 


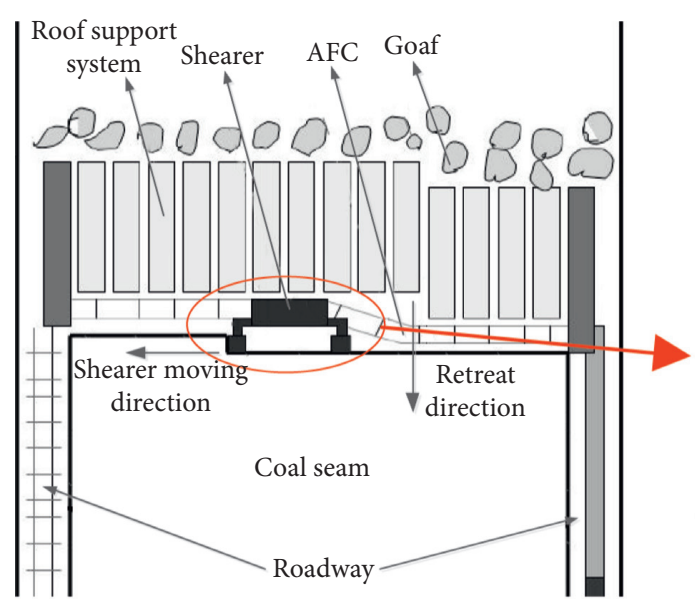

(a)

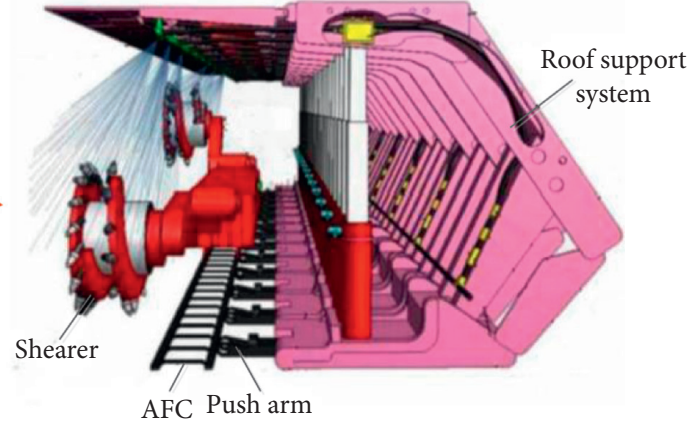

(b)

Figure 1: Typical plane view of (a) a longwall mining panel and (b) mining equipment [11].

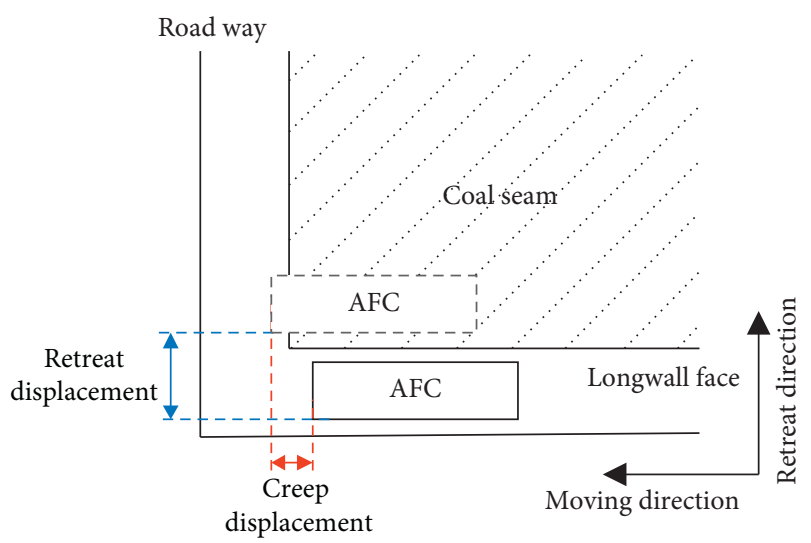

FIGURE 2: Diagram of the longwall retreat and creep displacements.

proposed three methods, including a laser radar [5], an Endress-Hauser FMR 250 radar [6-8], and the ultrawideband (UWB) positioning technology $[9,10]$, to determine those two displacements.

Reid et al. [5] installed the laser radar on the roadway conveyor structure linked to the AFC to scan the roadway. Two sets of scanning results were obtained before and after the AFC movement, and a scanmatching algorithm was used to obtain the longwall retreat and creep information. However, the laser propagation is greatly affected by the dust and moisture in the underground mine, so the measurement accuracy is not guaranteed. Hargrave et al. [6-8] used the EndressHauser FMR 250 radar to identify the bolt plates in the roadway coal wall to measure the longwall retreat and creep displacements in the Australian Beltana mine. Longwall creep displacement was measured by the distance variance between the radar and the coal wall of the roadway. In the Beltana mine, the number of bolt plates in the coal wall is a known environment mining parameter, and the radar identified the bolt plates to estimate the longwall retreat distance. However, this parameter may be unknown or inaccurate in most mines, which means this method is not widely applied. Tian et al. $[9,10]$ proposed the ultrawideband (UWB) positioning technology to determine the longwall retreat and creep displacements. Reference nodes were placed on the roadway with known coordinates, and a target node was installed on the shearer. When the shearer moved to the end of the longwall face, the position coordinate of target node was determined through the reference nodes with the time of arrival (TOA) or time difference of arrival (TDOA) algorithms. The longwall retreat and creep displacements were the coordinate variation of the target node between the adjacent cutting cycles. However, the communication between the reference nodes and the target node may be blocked by the coal seam, shearer body, roof support system, and so on, which can cause the range error. This makes the measured displacements of longwall retreat and creep unreliable.

In order to measure the longwall retreat and creep information reliably and accurately, an UWB radar imaging method is proposed in this study. Figure 3(a) shows the UWB radar imaging device. The two-direction guide rail is installed in the head of AFC, which moves with the advancing of longwall face. The two-direction guide rail enables the radar to move along the horizontal axis at different heights. The bolt plates (Figure 3(b)) in the coal wall of roadway are the targets to be imaged. Before the advancing of longwall face, the radar images bolt plates in a certain area of the roadway. After the advancing, the rotation table changes the direction of the radar beam, and the radar scans the same area of the roadway. According to the coordinate relationship of the targets in these two images, the longwall retreat and creep displacements are obtained. This radar imaging method makes use of the bolt plates fixed in the coal wall as the target points and requires no additional environment information. In addition, the UWB signal can propagate nearly without the influence of the dust and moisture. Based on this idea, this study designs the algorithm to image the targets and proposes the method to obtain the target three-dimensional (3D) coordinates 


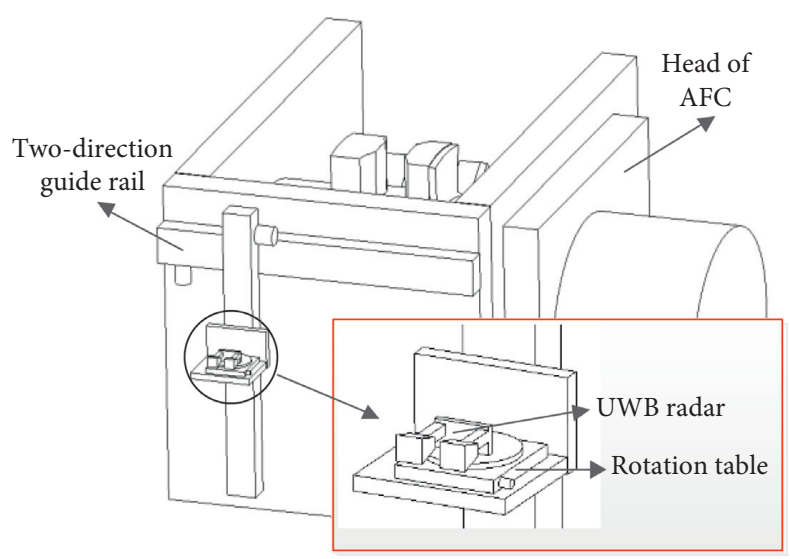

(a)

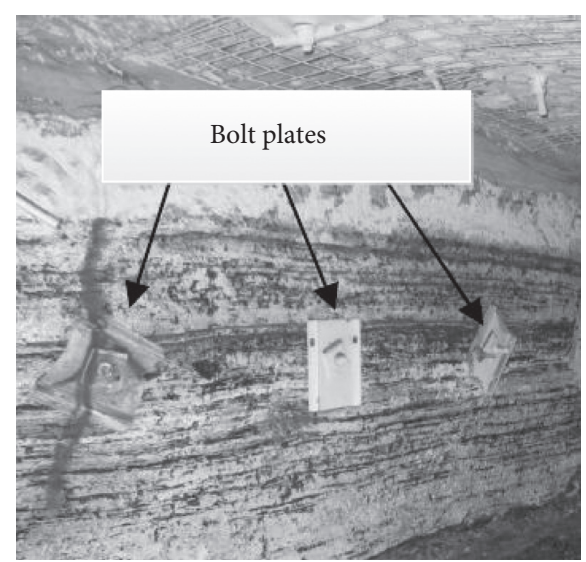

(b)

FIgURE 3: The diagram of (a) UWB radar imaging device and (b) the bolt plates in the coal wall of roadway [7].

and longwall retreat and creep displacements. The simulation and experiment results are performed to validate the feasibility of the radar imaging method for measuring the retreat and creep displacements.

The remainder of this paper is organized as follows. The radar imaging algorithm is described in Section 2. Section 3 gives the method to obtain the longwall retreat and creep displacements according to the imaging results. The simulation and experiment are performed in Section 4 to validate the proposed method. Finally, the conclusion is summarized in Section 5.

\section{Imaging Algorithm}

For high-resolution squinted synthetic aperture radar (SAR) imaging, various algorithms have been proposed in recent years, including range-Doppler (RD) algorithm [12-14], chirp scaling (CS) algorithm [15-21], omega-K algorithm $[22,23]$, and backprojection (BP) algorithm [24, 25]. Because of the high efficiency and precise error compensation, CS algorithm has been widely applied to process the squinted SAR data compared with other algorithms. In the range focusing, Sun et al. [15] used the squint-minimized function to reduce the range cell migration (RCM). Wu et al. [16] and Sun et al. [17] eliminated the RCM with the keystone transform (KT) in the bistatic and monostatic SAR, respectively. Zhong et al. [18] utilized the linear range walk correction (LRWC) and bulk RCM correction (BRCMC) to remove the RCM. In the azimuth focusing, [19-21] proposed the nonlinear CS (NLCS) algorithm to equalize the azimuthdependent frequency modulation (FM) rate. The RCM and azimuth-dependent FM rate make it difficult to obtain the high-resolution image. In this study, an algorithm is proposed to solve these two problems.

2.1. Signal Model. The geometric model of squinted SAR imaging is shown in Figure 4. The roadway coordinate

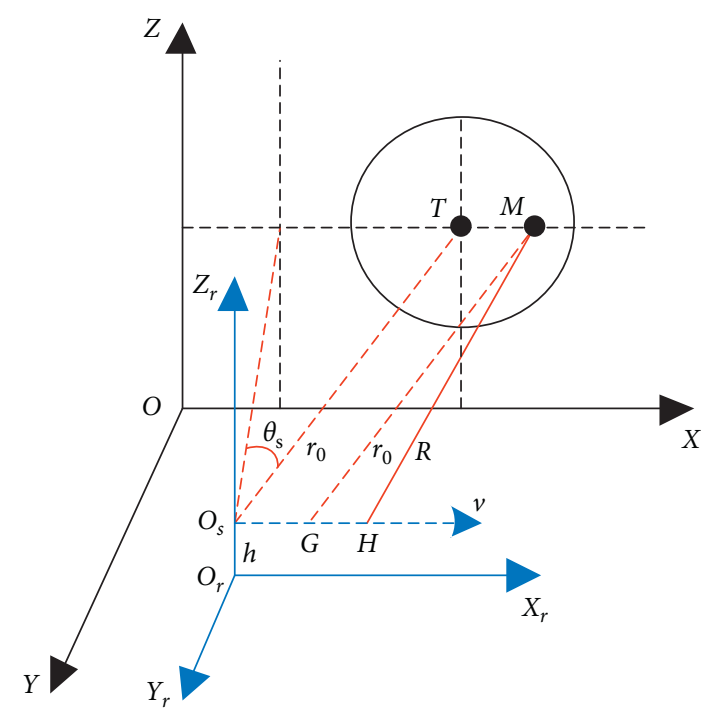

FIGURE 4: Geometric model of SAR imaging.

system is defined as $O X Y Z$, and the radar coordinate system is $O_{r} X_{r} Y_{r} Z_{r}$. The radar moves along the direction parallel to $X_{r}$-axis with a constant velocity $v . O_{s}$ is the center of synthetic aperture length at radar height $h$ where the azimuth time $t_{a}$ is equal to zero. The synthetic aperture length is the distance of radar movement. $\theta_{s}$ is the radar squint angle. The imaging scene is located on $O X Z$ plane. The point $T$ is the scene center, and $M$ is an arbitrary point. $r_{0}=\mathrm{GM}$ is the slant range from the target $M$ to the radar movement trajectory along the radar squint angle $\theta_{s}$. When the radar is at azimuth time $t_{a}$ which meets $v t_{a}=O_{s} H$, the instantaneous slant range of target $M$ is given by $R=H M$. The target $M$ is located at the azimuth time $t_{n}$ along the radar squint angle, which satisfies $v t_{n}=O_{s} G=\mathrm{TM}$.

The expression of the instantaneous range $R$ is given by 


$$
R\left(t_{a}, r_{0}\right)=\sqrt{v^{2}\left(t_{a}-t_{n}\right)^{2}+r_{0}^{2}-2 v r_{0}\left(t_{a}-t_{n}\right) \sin \theta_{s}} \approx r_{0}+\sum_{i=1}^{4} k_{i}\left(t_{a}-t_{n}\right)^{i},
$$

where $k_{i}$ is the coefficient of the Taylor polynomial.
It is assumed a Gaussian pulse is transmitted by the radar, and the demodulated echo signal $S_{0}\left(t_{r}, t_{a}\right)$ from target $M$ is given by

$$
S_{0}\left(t_{r}, t_{a}\right)=w_{r}\left(t_{r}-\frac{2 R\left(t_{a}, r_{0}\right)}{c}\right) w_{a}\left(t_{a}\right) p\left(t_{r}-\frac{2 R\left(t_{a}, r_{0}\right)}{c}\right) \exp \left(-j \frac{4 \pi f_{c}}{c} R\left(t_{a}, r_{0}\right)\right)
$$

where $t_{r}$ is the fast time, $t_{a}$ is the slow time, $w_{r}\left(t_{r}\right)$ is the range time envelope, $w_{a}\left(t_{a}\right)$ is the azimuth time envelope, $c$ is the speed of light, $p\left(t_{r}\right)$ is the Gaussian pulse, and $f_{c}$ is the carrier frequency.

2.2. Imaging Algorithm. The imaging algorithm contains the range focusing and azimuth focusing. In the range, the spatial-variant RCM is eliminated by the extended nonlinear
CS (ENLCS) algorithm proposed in [26] and the secondary range compression (SRC). In the azimuth focusing, this algorithm adds an azimuth compensation factor to overcome the azimuth distortion compared with [19-21].

2.2.1. Range Focusing. The echo signal (2) is transformed into the range-Doppler domain and yields

$$
\begin{aligned}
S_{1}\left(f_{r}, t_{a}\right) & =W_{r}\left(f_{r}\right) w_{a}\left(t_{a}\right) P\left(f_{r}\right) \exp \left(-j \frac{4 \pi\left(f_{c}+f_{r}\right)}{c} r_{0}\right) \exp \left(-j \frac{4 \pi\left(f_{c}+f\right)_{r}}{c} k_{1}\left(t_{a}-t_{n}\right)\right) \\
& \exp \left(-j \frac{4 \pi\left(f_{c}+f_{r}\right)}{c}\left(k_{2}\left(t_{a}-t_{n}\right)^{2}+k_{3}\left(t_{a}-t_{n}\right)^{3}+k_{4}\left(t_{a}-t_{n}\right)^{4}\right)\right),
\end{aligned}
$$

where $f_{r}$ is the range frequency, $W_{r}\left(f_{r}\right)$ is the range frequency envelope, and $P\left(f_{r}\right)$ is the frequency response of the Gaussian pulse.

The linear range walk correction (LRWC) is firstly used to remove the liner component of RCM, and LRWC function is given as follows:

$$
H_{1}\left(f_{r}, t_{a}\right)=\exp \left(-j \frac{4 \pi\left(f_{c}+f_{r}\right)}{c} v \sin \theta_{q} t_{a}\right)
$$

where $\theta_{q}$ is the squint angle of the reference point in the scene center. After LRWC, $r_{0}$ becomes $r_{\text {LRCM }}=r_{0}+v \sin \theta_{q} t_{n}$, and the coefficient $k_{1}$ of LRCM becomes $k_{1 \text { res }}=\left(-v \sin \theta_{s}\right)-\left(-v \sin \theta_{q}\right)$. In this study, $k_{1 \text { res }}$ is expressed as

$$
k_{1 \text { res }}=k_{10}+\frac{\partial k_{1 r e s}}{\partial t_{n}} t_{n}=k_{10}+k_{11} t_{n}
$$

where $k_{10}$ is the azimuth-invariant term and $k_{11}$ is the firstorder coefficient of the azimuth-variant term. Then, ENLCS function [26] is used to eliminate the azimuth-dependent RCM as follows:

$$
H_{2}\left(f_{r}, t_{a}\right)=\exp \left(j \frac{4 \pi\left(f_{c}+f_{r}\right)}{c} p_{2} t_{a}^{2}\right)
$$

where $p_{2}=k_{11} / 2$ is the coefficient of the ENLCS function. After ENLCS, transforming the result into the 2D frequency domain yields

$$
S_{2}\left(f_{r}, f_{a}\right)=W_{r}\left(f_{r}\right) W_{a}\left(f_{a}\right) P\left(f_{r}\right) \exp \left(j \varphi\left(f_{r}, f_{a}\right)\right) \exp \left(-j 2 \pi f_{a} t_{n}\right),
$$

where $W_{a}\left(f_{a}\right)$ is the azimuth frequency envelope and $\varphi\left(f_{r}, f_{a}\right)$ is expanded as a series of $f_{r}$ as :

$$
\varphi\left(f_{r}, f_{a}\right)=\varphi_{0} f_{a} \varphi_{1}\left(f_{a}\right) f_{r}+\varphi_{2}\left(f_{a}\right) f_{r}^{2}+\sum_{n=3}^{\infty} \varphi_{n}\left(f_{a}\right) f_{r}^{n}
$$

where $\varphi_{0}\left(f_{a}\right)$ is the azimuth modulation term and $\varphi_{i}\left(f_{a}\right)(i=1$, $2, \ldots)$ are the coefficients of the $i$-th range-dependent terms. Then, SRC is applied to remove the range-dependent RCM. Finally, range compression (RC) is operated to accomplish the range focusing. SRC and RC functions are as follows:

$$
\begin{gathered}
H_{3}\left(f_{r}, f_{a}\right)=\exp \left(-j\left(\varphi\left(f_{r}, f_{a}\right)-\varphi_{0}\left(f_{a}\right)\right)\right) \exp \left(-j \frac{4 \pi r_{\mathrm{LRCM}}}{c} f_{r}\right), \\
H_{4}\left(f_{r}\right)=\overline{P\left(f_{r}\right)} .
\end{gathered}
$$

Multiplying (9) and (10) with (7) and transforming the result into the range time and azimuth frequency domain yield 


$$
\begin{gathered}
S_{3}\left(t_{r}, f_{a}\right)=W_{a}\left(f_{a}\right) \sin c\left(B_{r}\left(t_{r}-\frac{2 r_{\mathrm{LRCM}}}{c}\right)\right) \\
\exp \left(j \varphi_{0}\left(f_{a}\right)\right) \exp \left(-j 2 \pi f_{a} t_{n}\right),
\end{gathered}
$$

where $\operatorname{sinc}(\cdot)$ is the sampling function and $B_{r}$ is the signal bandwidth.

2.2.2. Azimuth Focusing. Expanding $\varphi_{0}\left(f_{a}\right)$ into a series of $f_{a}$ yields

$$
\varphi_{0}\left(f_{a}\right) \approx \pi \eta_{0}+\pi \eta_{1} f_{a}+\pi \eta_{2} f_{a}^{2}+\pi \eta_{3} f_{a}^{3}+\pi \eta_{4} f_{a}^{4},
$$

where $\eta_{0}$ is the azimuth-independent term and $\eta_{1} \sim \eta_{4}$ are the coefficients of the azimuth-dependent terms. Firstly, an azimuth compensation factor is applied to compensate the azimuth distortion as follows:

$$
H_{5}\left(f_{a}\right)=\exp \left(-j \pi \eta_{1} f_{a}\right)
$$

Define $K_{a}=-1 / 2 \eta_{2}$, and expand $K_{a}$ as a series of $t_{n}$ as follows:

$$
K_{a}=K_{a 0}+K_{s 1} t_{n}+K_{s 2} t_{n}^{2}
$$

where $K_{a 0}$ is the azimuth-independent term of $K_{a}$ and $K_{S 1}$ and $K_{S 2}$ are the first-order and second-order coefficients of azimuth-dependent terms of $K_{a}$. Then, NLCS is utilized to eliminate the high-order Doppler phase and equalize the FM rate by multiplying a filter function in the range-Doppler domain and a scaling function in the $2 \mathrm{D}$ time domain. The filter and scaling functions are given as follows:

$$
\begin{aligned}
H_{6}\left(f_{a}\right) & =\exp \left(j \pi Y_{3} f_{a}^{3}+j \pi Y_{4} f_{a}^{4}\right), \\
H_{7}\left(t_{a}\right) & =\exp \left(j \pi q_{2} t_{a}^{2}+j \pi q_{3} t_{a}^{3}+j \pi q_{4} t_{a}^{4}\right),
\end{aligned}
$$

where the coefficients $Y_{3}, Y_{4}, q_{2}, q_{3}$, and $q_{4}$ can be found in [21]. After the azimuth compensation and NLCS, the signal in the range-Doppler domain becomes

$$
\begin{aligned}
S_{4}\left(t_{r}, f_{a}\right) & =W_{a}\left(\frac{f_{a}-q_{2} t_{n}}{K_{a}+q_{2}}\right) \sin c\left(B_{r}\left(t_{r}-\frac{2 r_{\mathrm{LRCM}}}{c}\right)\right) \exp \left(-j 2 \pi f_{a} \frac{t_{n}}{2 \alpha}\right) \\
& \exp \left(-j \pi \frac{1}{K_{a 0}+q_{2}} f_{a}^{2}+j \pi \frac{Y_{3} K_{a 0}^{3}+q_{3}}{\left(K_{a 0}+q_{2}\right)^{3}} f_{a}^{3}+j \pi \frac{Y_{4} K_{a 0}^{4}+q_{4}}{\left(K_{a 0}+q_{2}\right)^{4}} f_{a}^{4}\right),
\end{aligned}
$$

where $\alpha$ is the scaling factor. Finally, azimuth compression (AC) is operated to realize the azimuth focusing. AC function is given as

$$
\begin{aligned}
H_{8}\left(f_{a}\right)= & \exp \left(j \pi \frac{1}{K_{a 0}+q_{2}} f_{a}^{2}-j \pi \frac{Y_{3} K_{a 0}^{3}+q_{3}}{\left(K_{a 0}+q_{2}\right)^{3}} f_{a}^{3}\right. \\
& \left.-j \pi \frac{Y_{4} K_{a 0}^{4}+q_{4}}{\left(K_{a 0}+q_{2}\right)^{4}} f_{a}^{4}\right) .
\end{aligned}
$$

After AC, the result is transformed into the range time and azimuth time domain as follows:

$$
S_{5}\left(t_{r}, t_{a}\right)=\sin c\left(B_{r}\left(t_{r}-\frac{2 r_{\mathrm{LRCM}}}{c}\right)\right) \sin c\left(B_{a}\left(t_{a}-\frac{t_{n}}{2 \alpha}\right)\right)
$$

where $B_{a}$ is the Doppler bandwidth. The target is focused at $\left(t_{n} / 2 \alpha, r_{L R C M}\right)$, which needs to be corrected by geometry correction to obtain the real position by (18).

$$
t_{n c}=\frac{t_{n}}{2 \alpha} \frac{2 \alpha}{1} \quad r_{\mathrm{LC}}=r_{\mathrm{LRCM}}-\frac{t_{n}}{2 \alpha} \sin \theta_{q} .
$$

\section{Longwall Retreat and Creep Displacement Estimation}

The imaging result contains the target position information, including the slant range $r_{\mathrm{LC}}$ and azimuth time $t_{n c}$. In order to obtain the target 3D coordinate information, the radar needs to scan the target at different heights. Figure 5 shows the geometrical relationship of radar movement at $h_{1}$ and $h_{2}$ heights. $r_{\mathrm{LC} 1}$ and $r_{\mathrm{LC} 2}$ are the slant ranges of target $M$ when the radar moves at $h_{1}$ and $h_{2}$ heights, respectively. $l$ is the difference between $h_{1}$ and $h_{2}$, which is called the base line. With the cosine theorem, the relationship in the triangle $h_{1} M h_{2}$ satisfies as follows:

$$
r_{\mathrm{LC} 2}^{2}=r_{\mathrm{LC} 1}^{2}+l^{2}+2 r_{L C 1} l \cos \beta
$$

According to (20), $\beta$ is obtained as (21). Then, the height of target $M$ is given as (22).

$$
\begin{gathered}
\beta=\cos ^{-1}\left(\frac{r_{\mathrm{LC} 1}^{2}+l^{2}-r_{\mathrm{LC} 2}^{2}}{-2 r_{\mathrm{LC} 1} l}\right), \\
h_{p}=h_{1}-r_{\mathrm{LC} 1} \cos \beta .
\end{gathered}
$$

Through the above analysis, the $3 \mathrm{D}$ position coordinate of target $M$ in the $O_{r} X_{r} Y_{r} Z_{r}$ is obtained as

$$
P\left(v t_{n c}+r_{L C 1} \sin \beta \sin \theta_{q}, r_{L C 1} \sin \beta \cos \theta_{q}, h_{p}\right) \text {. }
$$

Similarly, after the advancing of longwall face, the coordinate $P^{\prime}$ of the target $M$ is also obtained. Therefore, the advancing displacement is $\Delta P=-\left(P^{\prime}-P\right)$. The longwall retreat and creep displacements are the components of the advancing displacement in the $X$-axis and $Y$-axis, respectively.

\section{Simulation and Experiment}

4.1. Simulation. To verify the effectiveness of the proposed method, a simulation with parameters in Table 1 was performed using MATLAB. Suppose that the longwall advancing displacement $\Delta P$ was $[0.80 \mathrm{~m}, 0.10 \mathrm{~m}, 0.00 \mathrm{~m}]$; that is, the longwall retreat and creep information were $0.80 \mathrm{~m}$ and $0.10 \mathrm{~m}$, respectively. There were three targets $\mathrm{A} \sim \mathrm{C}$ in the imaging scene. The coordinates of $\mathrm{A} \sim \mathrm{C}$ in the roadway coordinate system were $\mathrm{A}(0.786 \mathrm{~m}, 0.000 \mathrm{~m}, 0.300 \mathrm{~m})$, $\mathrm{B}(1.386 \mathrm{~m}, 0.000 \mathrm{~m}, 0.300 \mathrm{~m})$, and $\mathrm{C}(1.986 \mathrm{~m}, 0.000 \mathrm{~m}$, $0.300 \mathrm{~m}$ ), and the distribution of these targets was shown in Figure 6 . The target $B$ was chosen as the reference point. Before the advancing of longwall face, $X$-axis and $X_{r}$-axis 


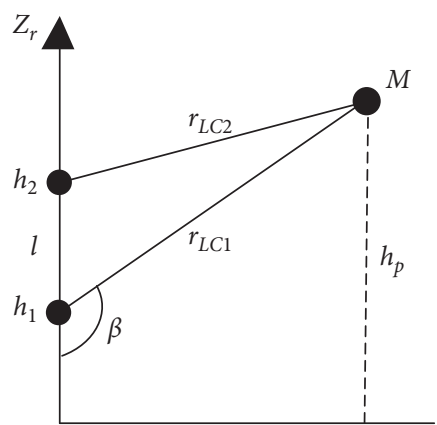

FIgURE 5: The geometrical relationship of radar movement at $h_{1}$ and $h_{2}$ heights.

TABle 1: Parameters in the first simulation.

\begin{tabular}{lccc}
\hline Parameters & Values & Parameters & Values \\
\hline Signal carrier frequency & $4.3 \mathrm{GHz}$ & Signal bandwidth & $1.7 \mathrm{GHz}$ \\
Sampling frequency & $20 \mathrm{~Hz}$ & Radar moving velocity & $0.15 \mathrm{~m} / \mathrm{s}$ \\
Synthetic aperture length & $2 \mathrm{~m}$ & Radar height & $0.15 / 0.30 \mathrm{~m}$ \\
Roadway width & $2.4 \mathrm{~m}$ & Advancing displacement & {$[0.80,0.10,0.00] \mathrm{m}$} \\
Radar squint angle & $30^{\circ} / 13.18^{\circ}$ & & \\
\hline
\end{tabular}

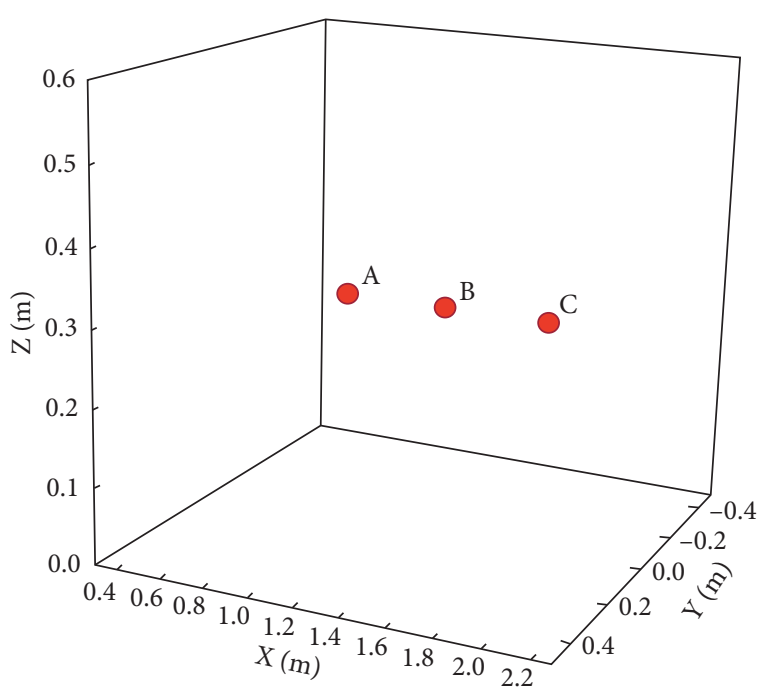

Figure 6: The distribution of targets A C.

were coincident, and other two axes in the OXYZ and $O_{r} X_{r} Y_{r} Z_{r}$ were parallel, respectively. The radar traveled at two heights $h_{1}=0.15 \mathrm{~m}$ and $h_{2}=0.30 \mathrm{~m}$ before and after the advancing of longwall face. The radar squint angle was $30^{\circ}$ before the advancing. After the advancing, the radar squint angle was changed to $13.18^{\circ}$ to make the reference point $\mathrm{B}$ imaged in the middle of the imaging result. It needed special explanation that all imaging results were obtained without any processing of the weighting function or side-lobe control.

Figure 7 shows the radar imaging results at $0.15 \mathrm{~m}$ and $0.30 \mathrm{~m}$ heights before and after the advancing of longwall face. It was seen that three targets were clearly imaged. Because of the range shift caused by LRWC process, the targets $\mathrm{A}$ and $\mathrm{C}$ were not imaged in the same range cell as target $B$ in the final imaging results. Target $B$ had no the shift along the range direction because target $B$ was selected as the reference point. The range shift was related with the target azimuth time and radar squint angle. The farther away the target is from the reference point in the azimuth direction, the greater the range shift is. When the azimuth time of target was less than that of reference point, the target had the shift along the range negative direction. When the azimuth time of target was larger than that of reference point, the target had the shift along the range positive direction. In addition, the range shift increased with the radar squint angle, which explained that the range shift of $\mathrm{A}$ and $\mathrm{C}$ relative to B in Figures 7(a) and 7(b) was greater than that in Figures $7(\mathrm{c})$ and $7(\mathrm{~d})$. The imaging results contained the targets azimuth and range information. Because the distances between the targets and the radar did not vary much when the radar scanned at $0.15 \mathrm{~m}$ and $0.30 \mathrm{~m}$ heights, there were no obvious changes for the target position between Figures 7(a) and 7(b), as well as Figures 7(c) and 7(d). Table 2 shows the target azimuth and range errors before and after the advancing in the simulation. Table 3 shows the target positions and its errors in the radar coordinate system before and after the advancing, and the advancing displacements according to the target positions. Whether before or after the advancing of longwall face, the position errors of $\mathrm{A} \sim \mathrm{C}$ in $Z_{r^{-}}$ axis were larger than the $X_{r}$-axis and $Y_{r}$-axis. Actually, the radar moving at different heights was equivalent to form the synthetic aperture along $Z_{r}$-axis. Because there were only two sampling data along $Z_{r}$-axis, the $Z_{r}$-axis position error was larger. If the radar moved at more heights, the $Z_{r}$-axis position error would be reduced. Theoretically, as long as there was one target, the advancing displacement could be obtained. Three targets were imaged in the simulation to improve the measuring accuracy of advancing displacement with average operation. In Table 3, three displacements were 


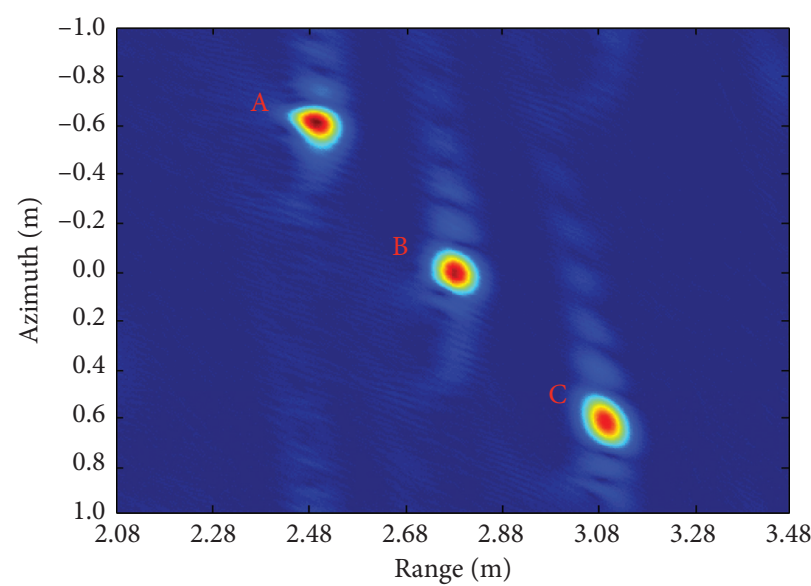

(a)

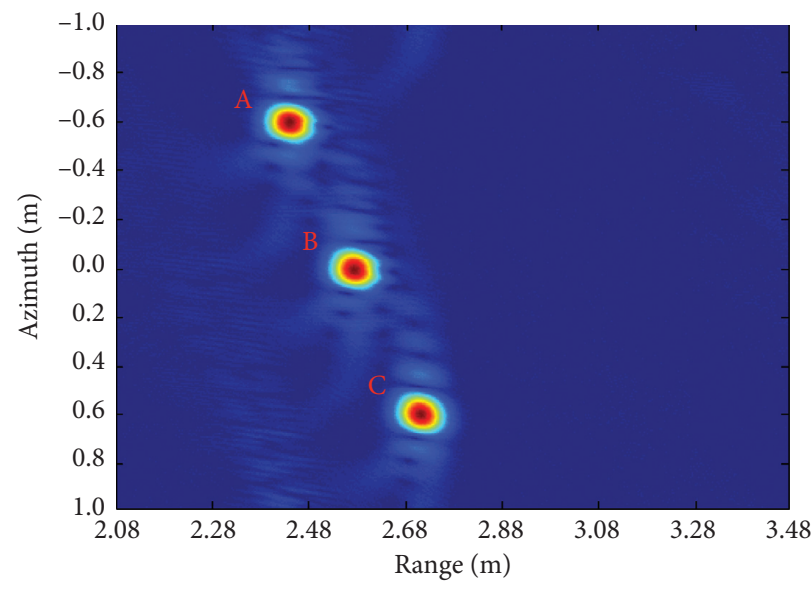

(c)

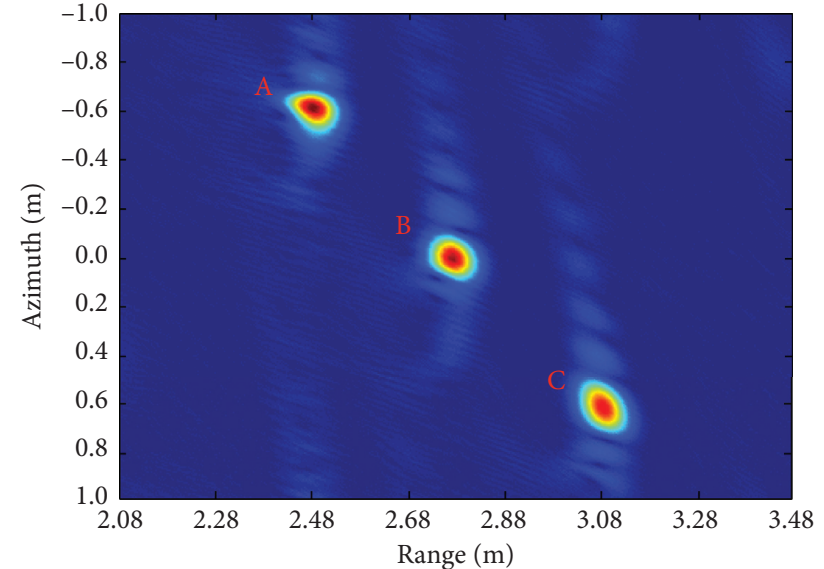

(b)

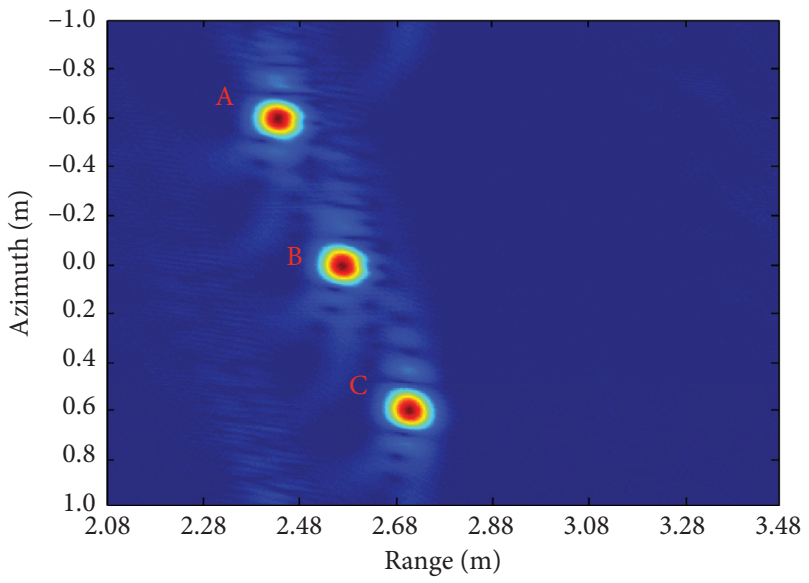

(d)

Figure 7: The radar imaging results at $0.15 \mathrm{~m}$ and $0.30 \mathrm{~m}$ heights before and after the advancing of longwall face. (a) $0.15 \mathrm{~m}$ before the advancing, (b) $0.30 \mathrm{~m}$ before the advancing, (c) $0.15 \mathrm{~m}$ after the advancing, and (d) $0.30 \mathrm{~m}$ after the advancing.

TABle 2: The target azimuth and range errors before and after the advancing in the first simulation.

\begin{tabular}{|c|c|c|c|c|c|c|c|}
\hline \multicolumn{2}{|c|}{ Height (m) } & \multicolumn{3}{|c|}{ Azimuth (m) } & \multicolumn{3}{|c|}{ Range (m) } \\
\hline & & $\mathrm{A}$ & B & $\mathrm{C}$ & $\mathrm{A}$ & $\mathrm{B}$ & $\mathrm{C}$ \\
\hline \multirow{2}{*}{ Before } & 0.15 & 0.024 & 0.004 & 0.010 & 0.022 & 0.002 & 0.009 \\
\hline & 0.30 & 0.024 & 0.008 & 0.022 & 0.021 & 0.001 & 0.006 \\
\hline \multirow{2}{*}{ After } & 0.15 & 0.002 & 0.014 & 0.004 & 0.005 & 0.004 & 0.003 \\
\hline & 0.30 & 0.004 & 0.010 & 0.008 & 0.006 & 0.001 & 0.004 \\
\hline
\end{tabular}

TABLE 3: Target positions and its errors in the radar coordinate system before and after the advancing, and the advancing displacements according to the target positions in the first simulation.

\begin{tabular}{lcccc}
\hline Targets & & Real position $(\mathrm{m})$ & Calculated position $(\mathrm{m})$ & Error $(\mathrm{m})$ \\
\hline \multirow{2}{*}{ A } & Before & $(0.786,-2.400,0.300)$ & $(0.772,-2.418,0.324)$ & $(-0.014,0.018,0.024)$ \\
& After & $(-0.014,-2.500,0.300)$ & $(-0.014,-2.506,0.277)$ & $(0.001,-0.006,-0.023)$ \\
& Displacement & $(0.800,0.100,0.000)$ & $(0.786,0.088,0.047)$ & $(-0.014,-0.012,0.047)$ \\
B & Before & $(1.386,-2.400,0.300)$ & $(1.380,-2.401,0.307)$ & $(-0.005,-0.001,0.007)$ \\
& After & $(0.586,-2.500,0.300)$ & $(0.597,-2.498,0.376)$ & $(0.012,0.002,0.076)$ \\
& Displacement & $(0.800,0.100,0.000)$ & $(0.783,0.097,-0.069)$ & $(-0.017,-0.003,-0.069)$ \\
C & Before & $(1.986,-2.400,0.300)$ & $(2.004,-2.404,0.369)$ & $(0.018,-0.004,0.069)$ \\
& After & $(1.186,-2.500,0.300)$ & $(1.193,-2.504,0.271)$ & $(0.007,-0.004,-0.029)$ \\
& Displacement & $(0.800,0.100,0.000)$ & $(0.811,0.100,0.098)$ & $(0.011,0.001,0.098)$ \\
\hline
\end{tabular}


obtained by targets $\mathrm{A}, \mathrm{B}$, and $\mathrm{C}$, respectively, which were $(0.786 \mathrm{~m}, 0.088 \mathrm{~m}, 0.047 \mathrm{~m}),(0.783 \mathrm{~m}, 0.097 \mathrm{~m},-0.069 \mathrm{~m})$, and $(0.811 \mathrm{~m}, 0.100 \mathrm{~m}, 0.098 \mathrm{~m})$. The advancing displacement with average operation was $0.794 \mathrm{~m}$ along $X$-axis, $0.095 \mathrm{~m}$ along $Y$-axis, and $0.025 \mathrm{~m}$ along $Z$-axis, whose errors were $-0.006 \mathrm{~m},-0.005 \mathrm{~m}$, and $0.025 \mathrm{~m}$, respectively. The advancing displacement error in $Z$-axis was larger than the other two axes because the target position error in $Z_{r}$-axis was larger than the $X_{r}$-axis and $Y_{r}$-axis.

Another simulation was performed according to the simulation parameters listed in Table 4. Except for the signal carrier frequency, bandwidth, and sampling frequency, other parameters were changed compared with the first simulation. Three targets $\mathrm{D} \sim \mathrm{F}$ were imaged in this simulation, whose coordinates in the roadway coordinate system were $\mathrm{D}(1.678 \mathrm{~m}, 0.000 \mathrm{~m}, 0.400 \mathrm{~m}), \mathrm{E}(1.678 \mathrm{~m}, 0.000 \mathrm{~m}$, $1.200 \mathrm{~m})$, and $\mathrm{F}(1.678 \mathrm{~m}, 0.000 \mathrm{~m}, 1.600 \mathrm{~m}$ ) (Figure 8). The target $\mathrm{E}$ was selected as the reference point. It was supposed that, before the advancing of longwall face, $X$-axis and $X_{r^{-}}$ axis were coincident, and other two axes in the $O X Y Z$ and $O_{r} X_{r} Y_{r} Z_{r}$ are parallel, respectively.

Figure 9 shows the radar imaging results at $0.05 \mathrm{~m}$ and $0.25 \mathrm{~m}$ heights before and after the advancing of longwall face. The target azimuth and range errors in the imaging results are listed in Table 5. Table 6 shows the target positions and its errors in the radar coordinate system before and after the advancing, and the advancing displacements according to the target positions. According to the calculated coordinates of targets $\mathrm{D} \sim \mathrm{F}$ before and after the advancing, three values of advancing displacement were obtained, which were $(0.697 \mathrm{~m},-0.100 \mathrm{~m}, 0.027 \mathrm{~m})$, $(0.691 \mathrm{~m},-0.096 \mathrm{~m}, 0.019 \mathrm{~m})$, and $(0.699 \mathrm{~m},-0.118 \mathrm{~m}$, $-0.033 \mathrm{~m})$, respectively. The average value of advancing displacement was $0.696 \mathrm{~m}$ along $X$-axis, $-0.105 \mathrm{~m}$ along $Y$ axis, and $0.004 \mathrm{~m}$ along $Z$-axis, and its errors were $0.004 \mathrm{~m}$, $0.005 \mathrm{~m}$, and $0.004 \mathrm{~m}$, respectively. In the above two simulations, the advancing displacement errors in $X$-axis and $Y$-axis were at millimeter lever.

4.2. Experiment. An experiment was conducted according to the parameters of the first simulation listed in Table 1. Figure 10 shows the diagram of the experiment site and imaging device. The roadway coordinate system $O X Y Z$ was established as shown in Figure 10(a). The radar coordinate system $O_{r} X_{r} Y_{r} Z_{r}$ was built in Figure 10(b), where $O_{r}$ is the center point of the horizontal axis of the two-direction guide rail. Three corner reflectors were used as the imaging targets, which had the strong scattering intensity. In the imaging device, the UWB module was connected to the data processing system by USB. The diagram of UWB module was shown in Figure 11, and the parameters of UWB module are listed in Table 7. The UWB module and the antenna were connected through a radio frequency line. The antenna was a pyramidal horn antenna, whose frequency was $3.1 \sim 4.8 \mathrm{GHz}$, gain was $10 \mathrm{~dB}$, and stationary wave was less than 1.5 . The antenna was installed in the rotation table, and the rotation table was installed in the two-direction guide rail. The rotation table could adjust the direction of the radar beam. The two-direction guide rail not only makes the antenna move along the horizontal axis, but also changes the antenna height along the vertical axis. The two-direction guide rail was placed in a mobile robot.

The coordinates of three corner reflectors in the roadway coordinate system were $\mathrm{A}(0.786 \mathrm{~m}, 0.000 \mathrm{~m}, 0.300 \mathrm{~m})$, $\mathrm{B}(1.386 \mathrm{~m}, 0.000 \mathrm{~m}, 0.300 \mathrm{~m})$, and $\mathrm{C}(1.986 \mathrm{~m}, 0.000 \mathrm{~m}$, $0.300 \mathrm{~m})$. The target $\mathrm{B}$ was chosen as the reference point. The horizontal distance between the corner reflectors and the antenna was $2.4 \mathrm{~m}$. A tapeline and a laser range finder were used to repeatedly determine the positions of the mobile robot, antenna, and the corner reflectors, which made the mean error of each position less than $0.005 \mathrm{~m}$ and the standard deviation less than $0.005 \mathrm{~m}$. Before the robot movement, $X$-axis and $X_{r}$-axis were coincident, and other two axes in the $O X Y Z$ and $O_{r} X_{r} Y_{r} Z_{r}$ were parallel, respectively. The velocity of radar moving was $0.15 \mathrm{~m} / \mathrm{s}$. The synthetic aperture length was $2 \mathrm{~m}$. The antenna aperture length was $0.14 \mathrm{~m}$. The radar scanned the corner reflectors at $0.15 \mathrm{~m}$ and $0.30 \mathrm{~m}$ height, respectively. It was supposed that the mobile robot moved $0.80 \mathrm{~m}$ along $X$-axis, $0.10 \mathrm{~m}$ along $Y$ axis, and $0.00 \mathrm{~m}$ along $Z$-axis. The radar squint angle was adjusted from $30^{\circ}$ before the robot movement to $13.18^{\circ}$ after the movement so that the reference point $\mathrm{B}$ was imaged in the center of the imaging result.

The detailed steps in the experiment are shown as follows:

Step 1: the mobile robot was located at $(0.000 \mathrm{~m}$, $2.400 \mathrm{~m}, 0.000 \mathrm{~m}$ ) in the roadway coordinate system, and the radar squint angle was $30^{\circ}$. The two-direction slipway made the radar antenna move along the horizontal axis at $0.15 \mathrm{~m}$ and $0.30 \mathrm{~m}$ heights, respectively.

Step 2: the mobile robot moved to $(0.800 \mathrm{~m}, 2.500 \mathrm{~m}$, $0.000 \mathrm{~m}$ ), and the radar squint angle was adjusted to $13.18^{\circ}$ by the rotation table.

Step 3: the radar antenna moved along the horizontal axis at $0.15 \mathrm{~m}$ and $0.30 \mathrm{~m}$ heights again.

Figure 12 shows the radar imaging results at $0.15 \mathrm{~m}$ and $0.30 \mathrm{~m}$ heights before and after the robot movement. The target B was clearly imaged. Because the target B was the reference point, its RCM and azimuth-dependent FM rate had the precise compensation. The targets $\mathrm{A}$ and $\mathrm{C}$ were far from the reference point along the azimuth direction, whose RCMs and azimuth-dependent FM rates could not be fully compensated. Therefore, the targets $\mathrm{A}$ and $\mathrm{C}$ had the defocus to some extent. Table 8 shows the target azimuth and range errors before and after the robot movement in the experiment. The bandwidth of radar signal was $1.7 \mathrm{GHz}$, so the range resolution was $0.088 \mathrm{~m}$. The azimuth resolution was $0.07 \mathrm{~m}$, which was half of the antenna aperture length. In the radar imaging result at $0.30 \mathrm{~m}$ height after the robot movement, the azimuth error of target A $(0.103 \mathrm{~m})$ was larger than the azimuth resolution, which might be caused by the fluctuation of radar moving velocity. Except for this, the azimuth and range errors of other targets were within the resolution. Table 9 shows the target positions and its errors in the radar coordinate system before and after the robot 
TABLE 4: Parameters in the second simulation.

\begin{tabular}{lccc}
\hline Parameters & Values & Parameters & Values \\
\hline Signal carrier frequency & $4.3 \mathrm{GHz}$ & Signal bandwidth & $1.7 \mathrm{GHz}$ \\
Sampling frequency & $20 \mathrm{~Hz}$ & Radar moving velocity & $0.2 \mathrm{~m} / \mathrm{s}$ \\
Synthetic aperture length & $1.8 \mathrm{~m}$ & Radar height & $0.05 / 0.25 \mathrm{~m}$ \\
Roadway width & $2.0 \mathrm{~m}$ & Advancing displacement & {$[0.70,-0.10,0.00] \mathrm{m}$} \\
Radar squint angle & $40^{\circ} / 27.24^{\circ}$ & & \\
\hline
\end{tabular}

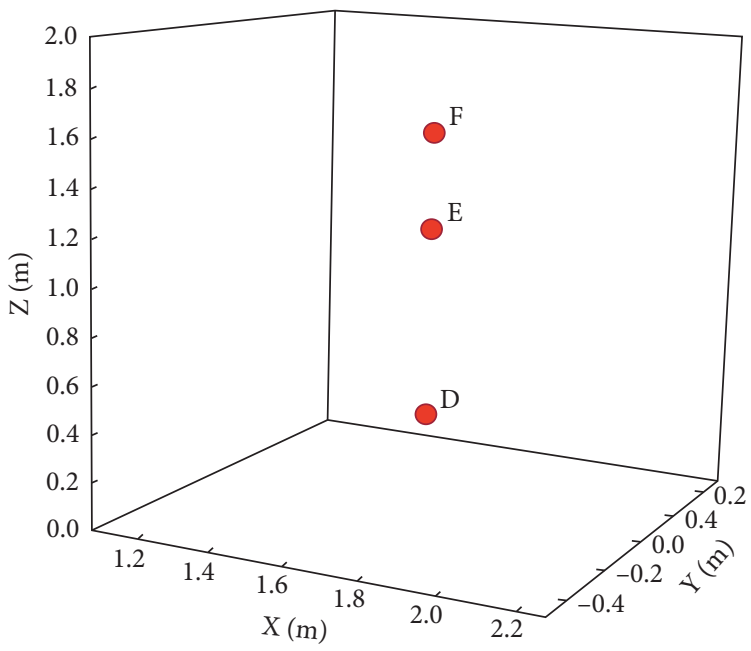

Figure 8: The distribution of targets D F.

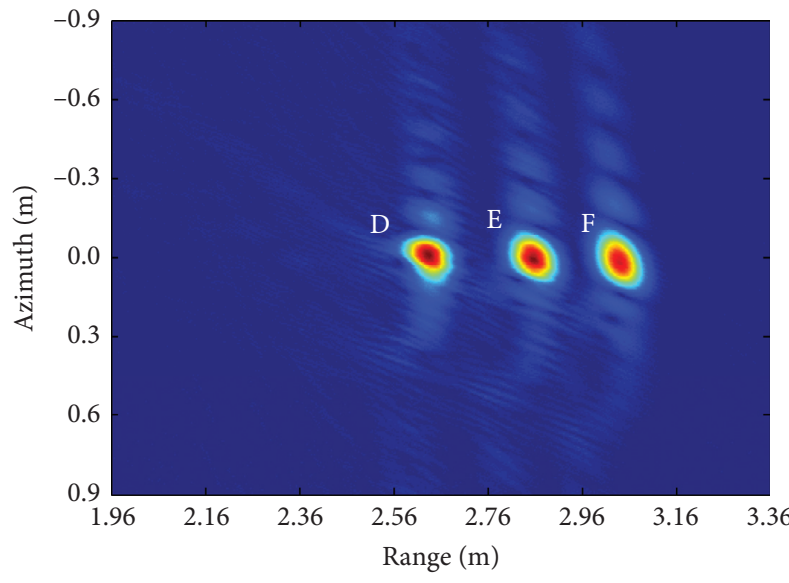

(a)

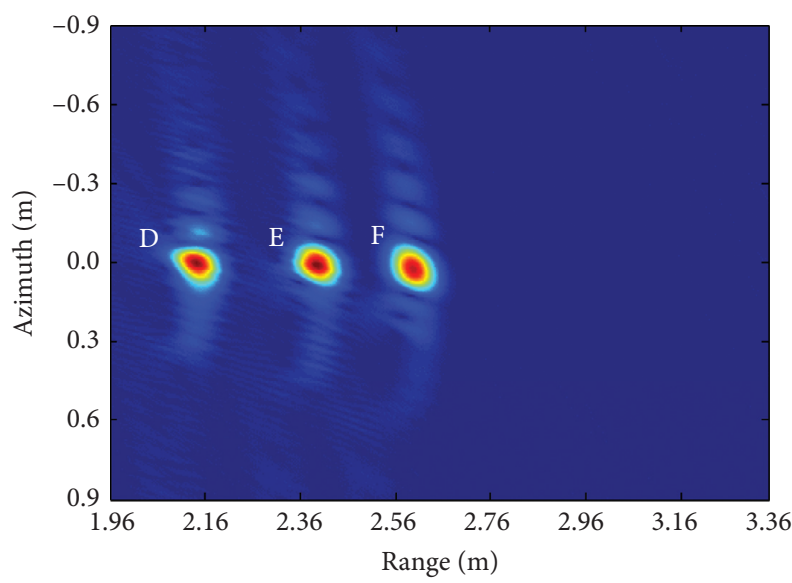

(c)

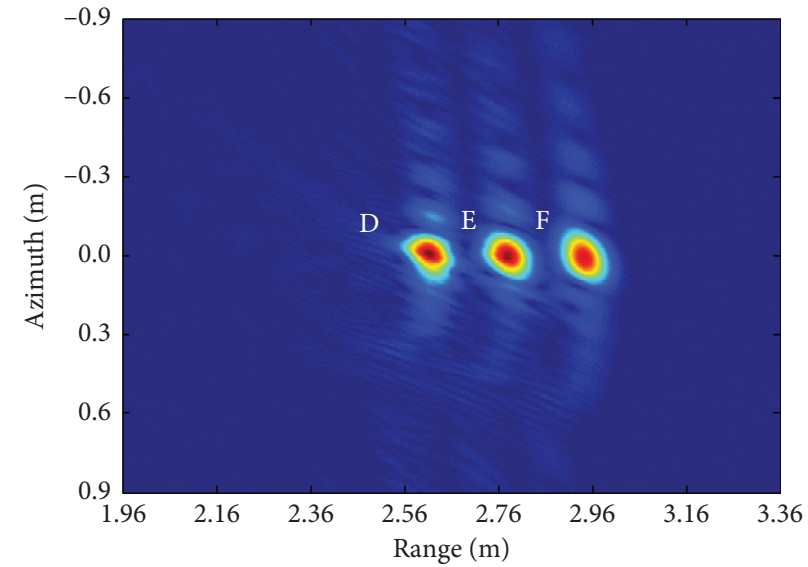

(b)

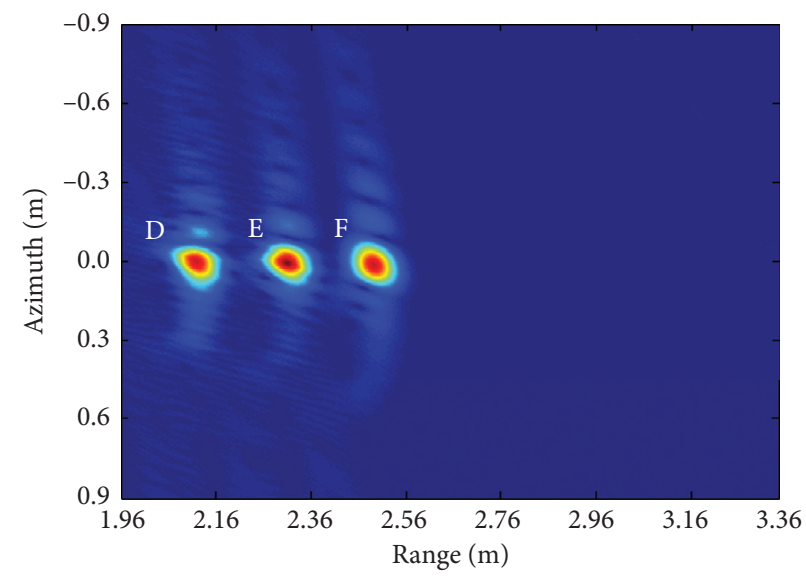

(d)

Figure 9: The radar imaging results at $0.05 \mathrm{~m}$ and $0.25 \mathrm{~m}$ heights before and after the advancing of longwall face. (a) $0.05 \mathrm{~m}$ before the advancing, (b) $0.25 \mathrm{~m}$ before the advancing, (c) $0.05 \mathrm{~m}$ after the advancing, and (d) $0.25 \mathrm{~m}$ after the advancing. 
TABLE 5: The target azimuth and range errors before and after the advancing in the second simulation.

\begin{tabular}{|c|c|c|c|c|c|c|c|}
\hline \multirow{2}{*}{\multicolumn{2}{|c|}{ Height (m) }} & \multicolumn{3}{|c|}{ Azimuth (m) } & \multicolumn{3}{|c|}{ Range (m) } \\
\hline & & $\mathrm{D}$ & $\mathrm{E}$ & $\mathrm{F}$ & $\mathrm{D}$ & $\mathrm{E}$ & $\mathrm{F}$ \\
\hline \multirow{2}{*}{ Before } & 0.05 & 0.008 & 0.004 & 0.001 & 0.005 & 0.001 & 0.001 \\
\hline & 0.25 & 0.008 & 0.008 & 0.004 & 0.005 & 0.001 & 0.001 \\
\hline \multirow{2}{*}{ After } & 0.05 & 0.008 & 0.004 & 0.016 & 0.009 & 0.001 & 0.001 \\
\hline & 0.25 & 0.004 & 0.001 & 0.012 & 0.007 & 0.001 & 0.001 \\
\hline
\end{tabular}

TABle 6: Target positions and its errors in the radar coordinate system before and after the advancing, and the advancing displacements according to the target positions in the second simulation.

\begin{tabular}{lcccc}
\hline Targets & & Real position $(\mathrm{m})$ & Calculated position $(\mathrm{m})$ & Error $(\mathrm{m})$ \\
\hline $\mathrm{D}$ & Before & $(1.678,-2.000,0.400)$ & $(1.667,-1.996,0.404)$ & $(-0.012,0.004,0.004)$ \\
& After & $(0.978,-1.900,0.400)$ & $(0.970,-1.896,0.377)$ & $(-0.008,0.005,-0.023)$ \\
& Displacement & $(0.700,-0.100,0.000)$ & $(0.697,-0.100,0.027)$ & $(-0.003,0.001,0.027)$ \\
E & Before & $(1.678,-2.000,1.200)$ & $(1.669,-1.991,1.230)$ & $(-0.010,0.009,0.030)$ \\
& After & $(0.978,-1.900,1.200)$ & $(0.978,-1.895,1.211)$ & $(0.001,0.005,0.011)$ \\
& Displacement & $(0.700,-0.100,0.000)$ & $(0.691,-0.096,0.019)$ & $(-0.009,0.004,0.019)$ \\
F & Before & $(1.678,-2.000,1.600)$ & $(1.685,-2.006,1.586)$ & $(0.007,-0.006,-0.015)$ \\
& After & $(0.978,-1.900,1.600)$ & $(0.986,-1.888,1.619)$ & $(0.008,0.012,0.019)$ \\
& Displacement & $(0.700,-0.100,0.000)$ & $(0.699,-0.118,-0.033)$ & $(-0.001,-0.018,-0.033)$ \\
\hline
\end{tabular}

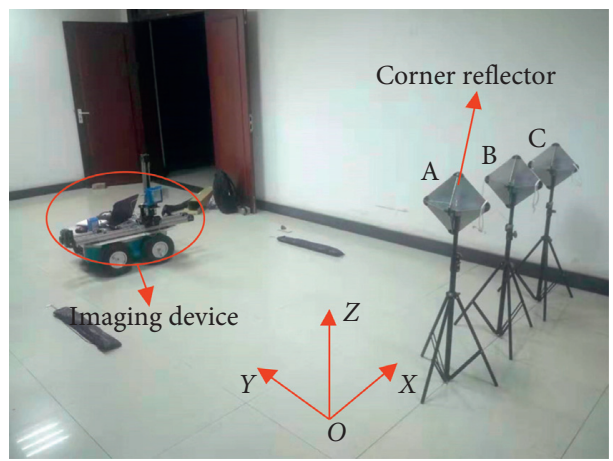

(a)

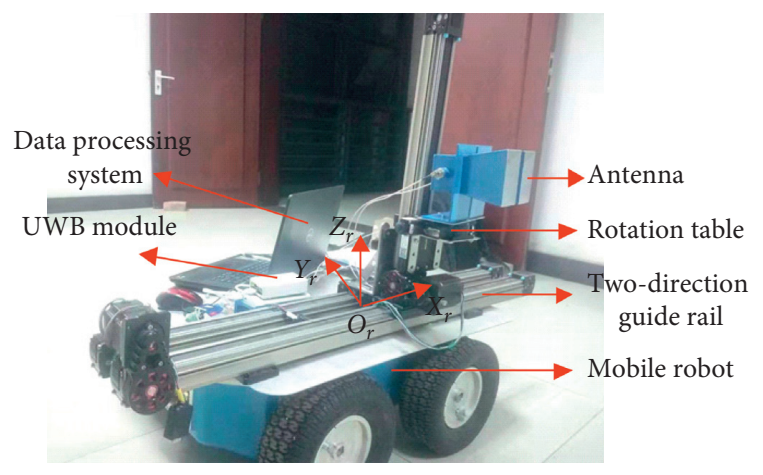

(b)

Figure 10: The diagram of the experiment site and device. (a) Experiment site and (b) imaging device.

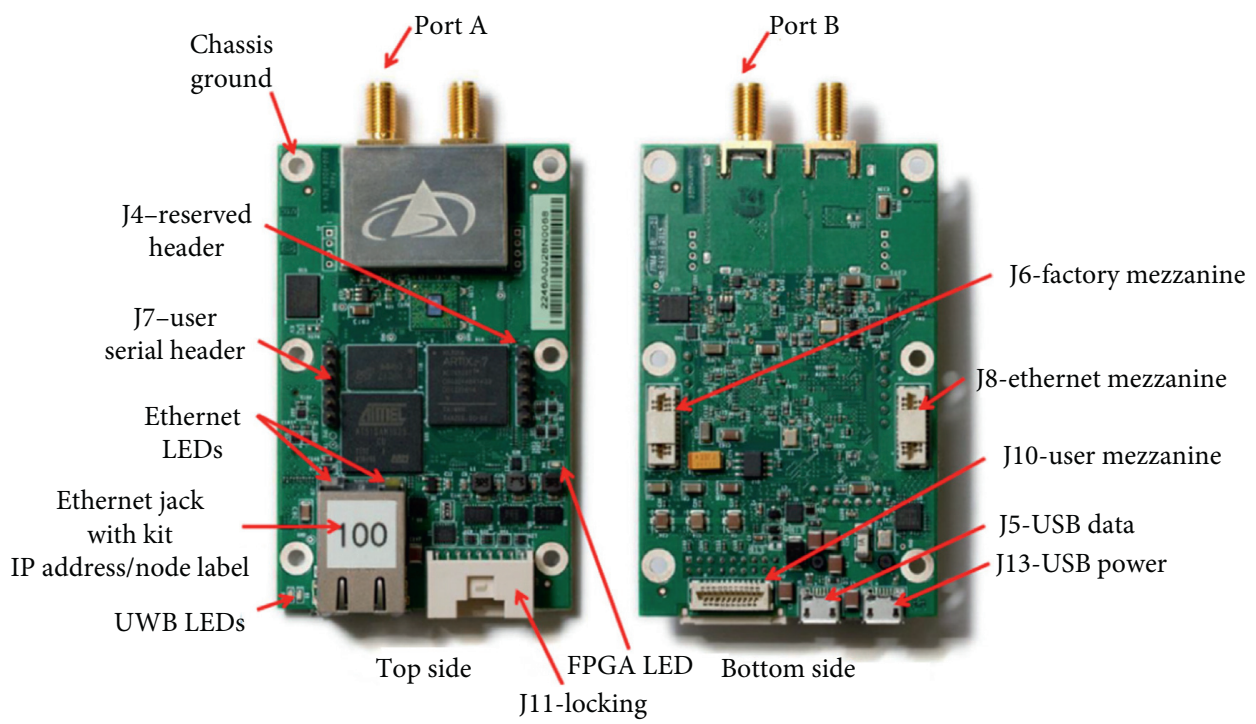

Figure 11: The diagram of the UWB module. 
TABLE 7: The parameters of the UWB module.

\begin{tabular}{lc}
\hline Parameters & Value \\
\hline Dimension & $89 \times 56 \mathrm{~mm}$ \\
Input power & $5.0 \mathrm{~V}$ \\
Average transmit power & $50 \mathrm{uW}$ \\
Radio frequency & $3.1 \sim 4.8 \mathrm{GHz}$ \\
Center frequency & $4.3 \mathrm{GHz}$ \\
Sample frequency & $20 \mathrm{~Hz}$ \\
Max data throughput & $19.2 \mathrm{kbps}$ to $612 \mathrm{kbps}$ \\
\hline
\end{tabular}

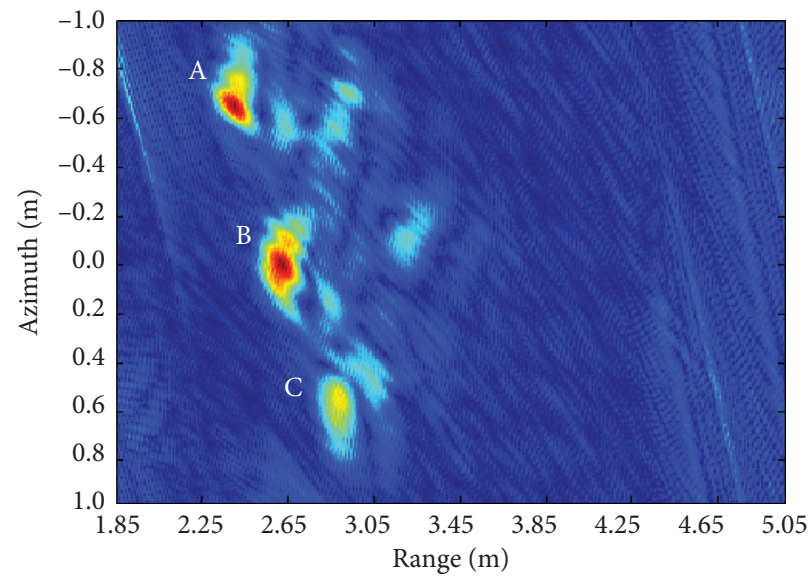

(a)

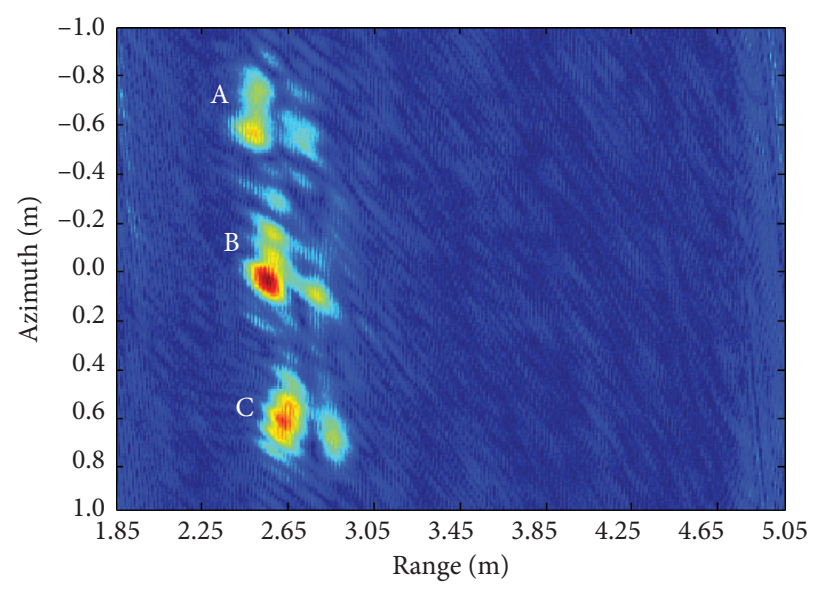

(c)

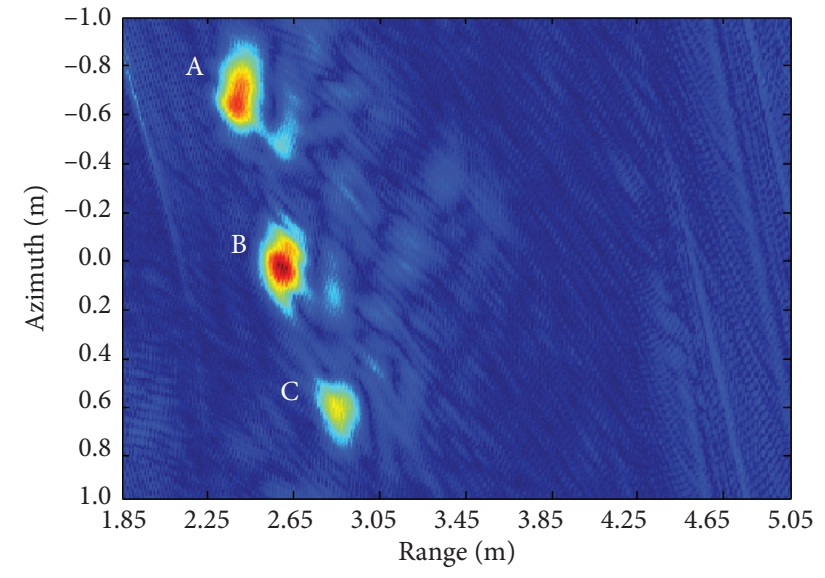

(b)

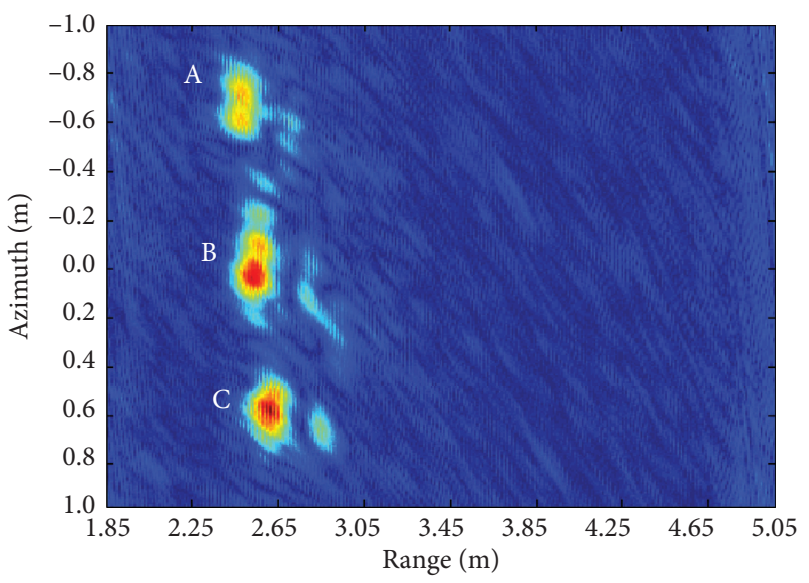

(d)

FIGURE 12: The radar imaging results at $0.15 \mathrm{~m}$ and $0.30 \mathrm{~m}$ heights before and after the robot movement. (a) $0.15 \mathrm{~m}$ before the movement, (b) $0.30 \mathrm{~m}$ before the movement, (c) $0.15 \mathrm{~m}$ after the movement, and (d) $0.30 \mathrm{~m}$ after the movement.

movement, and the movement displacements according to the target positions. Except for the target A before the movement, the $Z$-axis position errors of other targets were larger than the $X$-axis and $Y$-axis, which was explained in the simulation. According to the calculated position coordinates of $\mathrm{A} \sim \mathrm{C}$ in the radar coordinate system before and after the movement, three movement displacements were $(0.759 \mathrm{~m}$, $0.174 \mathrm{~m}, \quad 0.281 \mathrm{~m}), \quad(0.742 \mathrm{~m}, \quad 0.110 \mathrm{~m},-0.146 \mathrm{~m})$, and $(0.730 \mathrm{~m}, 0.137 \mathrm{~m}, 0.720 \mathrm{~m})$, respectively. The average value of movement displacement was obtained, which were $0.742 \mathrm{~m}$ along $X$-axis, $0.140 \mathrm{~m}$ along $Y$-axis, and $-0.285 \mathrm{~m}$ along $Z$-axis. The errors of movement displacement were
$0.058 \mathrm{~m}, 0.040 \mathrm{~m}$, and $0.285 \mathrm{~m}$, respectively. The movement displacement error in $Z$-axis was larger than $X$-axis and $Y$ axis. If the radar moved at more heights, the $Z$-axis error would decrease.

UWB radar imaging result is shown in different colors according to the scattering intensity of the object. Because the corner reflector has stronger scattering intensity than other objects in the experiment, three corner reflectors were clearly imaged. In the experiment, the tripods and other objects in the room had weaker scattering intensity than the corner reflectors, which explained that only three corner reflectors are clearly imaged in Figure 12. Therefore, 
TABLE 8: The target azimuth and range errors before and after the robot movement in the experiment.

\begin{tabular}{|c|c|c|c|c|c|c|c|}
\hline \multicolumn{2}{|c|}{ Height (m) } & \multicolumn{3}{|c|}{ Azimuth (m) } & \multicolumn{3}{|c|}{ Range (m) } \\
\hline & & $\mathrm{A}$ & B & $\mathrm{C}$ & $\mathrm{A}$ & $\mathrm{B}$ & $\mathrm{C}$ \\
\hline \multirow{2}{*}{ Before } & 0.15 & 0.052 & 0.015 & 0.042 & 0.041 & 0.071 & 0.007 \\
\hline & 0.30 & 0.045 & 0.036 & 0.045 & 0.038 & 0.083 & 0.044 \\
\hline \multirow{2}{*}{ After } & 0.15 & 0.042 & 0.058 & 0.038 & 0.044 & 0.023 & 0.082 \\
\hline & 0.30 & 0.103 & 0.051 & 0.009 & 0.063 & 0.045 & 0.080 \\
\hline
\end{tabular}

TABLE 9: Target positions and its errors in the radar coordinate system before and after the robot movement, and the movement displacements according to the target positions.

\begin{tabular}{lcccc}
\hline Targets & & Real position $(\mathrm{m})$ & Calculated position $(\mathrm{m})$ & Error $(\mathrm{m})$ \\
\hline \multirow{2}{*}{ A } & Before & $(0.786,-2.400,0.300)$ & $(0.724,-2.367,0.248)$ & $(-0.068,-0.033,-0.052)$ \\
& After & $(-0.014,-2.500,0.300)$ & $(-0.035,-2.541,-0.033)$ & $(-0.021,-0.041,-0.333)$ \\
& Displacement & $(0.800,0.100,0.000)$ & $(0.759,0.174,0.281)$ & $(-0.041,0.074,0.281)$ \\
B & Before & $(1.386,-2.400,0.300)$ & $(1.366,-2.321,0.515)$ & $(-0.020,-0.079,0.215)$ \\
& After & $(0.586,-2.500,0.300)$ & $(0.624,-2.431,0.661)$ & $(0.038,0.069,0.361)$ \\
& Displacement & $(0.800,0.100,0.000)$ & $(0.742,0.110,-0.146)$ & $(-0.058,0.010,-0.146)$ \\
C & Before & $(1.986,-2.400,0.300)$ & $(1.921,-2.285,0.987)$ & $(-0.065,-0.115,0.687)$ \\
& After & $(1.186,-2.500,0.300)$ & $(1.191,-2.422,0.267)$ & $(0.005,-0.078,-0.033)$ \\
& Displacement & $(0.800,0.100,0.000)$ & $(0.730,0.137,0.720)$ & $(-0.070,0.037,0.720)$ \\
\hline
\end{tabular}

the tripods and others in the room environment little affected the imaging result. As mentioned above, the position errors of the imaging device and corner reflectors were corrected with the tapeline and laser range finder. In the experiment, the radar velocity fluctuation and the signal attenuation caused the target azimuth and range errors (Table 8), respectively, which were larger than that in the simulation (Tables 2 and 5). UWB pulse shape also had the influence on the image resolution. In [27], Oloumi et al. showed the Gaussian pulse provided better image resolution compared with the chirp pulse. Therefore, the Gaussian pulse proposed in [28] was used in this paper. In the next, increasing the signal transmitting power and bandwidth will be operated to improve the imaging quality. Other imaging algorithms including the back-projection algorithm and omega-k algorithm will be modified to reduce the measurement errors.

\section{Conclusion}

This study proposes an UWB radar imaging method to determine the longwall retreat and creep displacements. The SAR imaging algorithm including the range focusing and azimuth focusing is designed to image the targets. According to the radar imaging results at different heights, the target $3 \mathrm{D}$ coordinates and the longwall retreat and creep displacements are obtained. In two simulations, the retreat and creep displacement errors are $0.006 \mathrm{~m}$, $0.005 \mathrm{~m}$ and $0.004 \mathrm{~m}, 0.005 \mathrm{~m}$, respectively. In the experiment, the retreat and creep displacement errors are $0.058 \mathrm{~m}$ and $0.040 \mathrm{~m}$, respectively. The radar velocity fluctuation and the signal attenuation cause the target azimuth and range errors, respectively. Next, we will improve SNR and signal bandwidth to reduce the measurement error. In addition, modified back-projection algorithm and omega-k algorithm will be operated to obtain high-resolution image.

\section{Data Availability}

The data used to support the findings of this study are available from the corresponding author upon request.

\section{Conflicts of Interest}

The authors declare that there are no conflicts of interest regarding the publication of this paper.

\section{Acknowledgments}

This research was financially supported by the funds of the Natural Science Foundation of China (Grant nos. 51874279 and 51974290) and by the Priority Academic Program Development of Jiangsu Higher Education Institutions (PAPD).

\section{References}

[1] R. D. Singh, Principles and Practices of Modern Coal Mining, New Age International, Bengaluru, Karnataka, 2005.

[2] M. He, G. Zhu, and Z. Guo, "Longwall mining "cutting cantilever beam theory" and 110 mining method in ChinaThe third mining science innovation," Journal of Rock Mechanics and Geotechnical Engineering, vol. 7, no. 5, pp. 483492, 2015.

[3] S. S. Peng, Longwall Mining, CRC Press, Boca Raton, FL, USA, 2019.

[4] G. A. Einicke, J. C. Ralston, C. O. Hargrave, D. C. Reid, and D. W. Hainsworth, "Longwall mining automation an application of minimum-variance smoothing [Applications of Control]," IEEE Control Systems, vol. 28, no. 6, pp. 28-37, 2008. 
[5] D. Reid, J. Ralston, M. Dunn et al., "Longwall shearer automation: from research to reality," in Machine Vision and Mechatronics in Practice, pp. 49-57, Springer, Heidelberg, Germany, 2015.

[6] C. O. Hargrave, C. A. James, and J. C. Ralston, "Infrastructure-based localisation of automated coal mining equipment," International Journal of Coal Science \& Technology, vol. 4, no. 3, pp. 252-261, 2017.

[7] C. O. Hargrave, N. V. Shuley, J. C. Ralston et al., "Radar level sensor for longwall creep and retreat measurement," in Proceedings of the IEEE Industry Applications Annual Meeting, pp. 2102-2109, IEEE, New Orleans, LA, USA, September 2007.

[8] C. O. Hargrave, I. V. L. Clarkson, and H. S. Lui, "Radar waypoint navigator for underground mining," in Proceedings of the 8th European conference on antennas and propagation (EuCAP 2014), IEEE, The Hague, Netherlands, pp. 3587-3591, April 2014.

[9] Ye Tian, Research on UWB Positioning System of Shearer in Longwall Mining Workface, China University of Mining and Technology, Xuzhou, China, 2018, in Chinese.

[10] Ye Tian, S. Wang, W. Liu et al., "Experimental study and prediction model of UWB non-line of sight ranging error in $\mathrm{L}$ type space," Coal Mining Technology, vol. 23, no. 2, pp. 11-14, 2018.

[11] S. Hao, S. Wang, R. Malekian, B. Zhang, W. Liu, and Z. Li, "A geometry surveying model and instrument of a scraper conveyor in unmanned longwall mining faces," IEEE Access, vol. 5, pp. 4095-4103, 2017.

[12] R. Bamler, "A comparison of range-Doppler and wavenumber domain SAR focusing algorithms," IEEE Transactions on Geoscience and Remote Sensing, vol. 30, no. 4, pp. 706-713, 1992.

[13] I.-P. Hong and H.-K. Park, "High level SW and HW mapping method of the space-based SAR processor using RDA," Signal Processing, vol. 84, no. 5, pp. 943-949, 2004.

[14] H. Zhong and X. Liu, "An effective focusing approach for azimuth invariant bistatic SAR processing," Signal Processing, vol. 90, no. 1, pp. 395-404, 2010.

[15] G. Sun, X. Jiang, M. Xing, Z.-j. Qiao, Y. Wu, and Z. Bao, "Focus improvement of highly squinted data based on azimuth nonlinear scaling," IEEE Transactions on Geoscience and Remote Sensing, vol. 49, no. 6, pp. 2308-2322, 2011.

[16] J. Wu, Z. Li, Y. Huang et al., "Focusing bistatic forwardlooking SAR with stationary transmitter based on keystone transform and nonlinear chirp scaling," IEEE Geoscience and Remote Sensing Letters, vol. 11, no. 1, pp. 148-152, 2014.

[17] Z. Sun, J. Wu, Z. Li et al., "Highly squint SAR data focusing based on keystone transform and azimuth extended nonlinear chirp scaling," IEEE Geoscience and Remote Sensing Letters, vol. 12, no. 1, pp. 145-149, 2015.

[18] H. Zhong, Y. Zhang, Y. Chang, E. Liu, X. Tang, and J. Zhang, "Focus high-resolution highly squint SAR data using azimuth-variant residual RCMC and extended nonlinear chirp scaling based on a new circle model," IEEE Geoscience and Remote Sensing Letters, vol. 15, no. 4, pp. 547-551, 2018.

[19] S. Chen, H. Zhao, S. Zhang, and Y. Chen, "An extended nonlinear chirp scaling algorithm for missile borne SAR imaging," Signal Processing, vol. 99, pp. 58-68, 2014.

[20] F. H. Wong, I. G. Cumming, and Y. L. Yew Lam Neo, "Focusing bistatic SAR data using the nonlinear chirp scaling algorithm," IEEE Transactions on Geoscience and Remote Sensing, vol. 46, no. 9, pp. 2493-2505, 2008.
[21] D. An, X. Huang, T. Jin, and Z. Zhou, "Extended nonlinear chirp scaling algorithm for high-resolution highly squint SAR data focusing," IEEE Transactions on Geoscience and Remote Sensing, vol. 50, no. 9, pp. 3595-3609, 2012.

[22] H. S. Shin and J. T. Lim, "Omega-K algorithm for spaceborne spotlight SAR imaging," IEEE Geoscience and Remote Sensing Letters, vol. 9, no. 3, pp. 343-347, 2012.

[23] T. Xiong, M. Xing, X. G. Xia et al., "New applications of omega-K algorithm for SAR data processing using effective wavelength at high squint," IEEE Transactions on Geoscience and Remote Sensing, vol. 51, no. 5, pp. 3156-3169, 2013.

[24] J. N. Ash, "An autofocus method for backprojection imagery in synthetic aperture radar," IEEE Geoscience and Remote Sensing Letters, vol. 9, no. 1, pp. 104-108, 2012.

[25] L. Zhang, H. Li, Z. Qiao et al., "A fast BP algorithm with wavenumber spectrum fusion for high-resolution spotlight SAR imaging," IEEE Geoscience and Remote Sensing Letters, vol. 11, no. 9, pp. 1460-1464, 2014.

[26] D. Li, H. Lin, H. Liu et al., "Focus improvement for highresolution highly squinted SAR imaging based on 2-D spatialvariant linear and quadratic RCMs correction and azimuthdependent Doppler equalization," IEEE Journal of Selected Topics in Applied Earth Observations and Remote Sensing, vol. 10, no. 1, pp. 168-183, 2017.

[27] D. Oloumi, J.-W. Ting, and K. Rambabu, "Design of pulse characteristics for near-field UWB-SAR imaging," IEEE Transactions on Microwave Theory and Techniques, vol. 64, no. 8, pp. 2684-2693, 2016.

[28] T. Truong, A. Dinh, and K. Wahid, "An ultra-wideband frequency system for non-destructive root imaging," Sensors, vol. 18 , no. 8, p. 2438, 2018. 